\title{
Relationship of personality and physique to plasma cortisol levels in response to anxiety
}

\author{
P. K. BRIDGES AND M. T. JONES \\ From the Department of Psychological Medicine, Royal Free Hospital, London, W.C.1, and the \\ Sherrington School of Physiology, St. Thomas's Hospital, London
}

A relationship between physical constitution and temperamental traits has been described from the earliest times. Modern concepts began with the work of Kretschmer (1936) associating types of physique with personality qualities in relation to some psychiatric illnesses. The main problem encountered in these studies has been the difficulty in measuring personality and body-build with satisfactory objectivity. The history of the work concerning anthropomorphology and the various classifications suggested have been reviewed by Rees (1960). A useful advance was made by Sheldon (1940) who postulated three physical dimensions-endomorphy, mesomorphy and ectomorphy - and he later reported associations between physique and temperament, with high correlation coefficients found between variation along the physical and psychological dimensions (Sheldon, 1942). But Sheldon's method of somatotyping is basically photographic and does not entirely eliminate a subjective element. In order to improve objectivity of assessment Parnell (1958) modified Sheldon's work and developed his system of phenotyping, using a seven-point scale for each of the similar dimensions of fat, muscularity, and linearity $(F, M, L)$, and this method has been employed in the present study.

In a previous report (Bridges and Jones, 1967) it was noted that there have been a number of studies in which physiological variables, such as plasma cortisol levels and urinary catecholamine excretion, have been used as measures of anxiety in various stressful situations, and the results of such work have tended to show considerable variation between subjects, which suggests that the stresses may not always have been adequate to produce measurable anxiety or that there may have been individual differences in responsiveness. In the earlier study we observed medical students taking a viva voce examination which, as it is not merely a contrived situation, is likely to act as a reliable and considerable psychological stress. Therefore it may be assumed that any variation in responsiveness is probably due to individual factors, the nature of which we attempted to investigate. Body-build and personality are two such possible factors which were each measured by two methods in that study and related to the plasma cortisol concentrations occurring after the examination. It was found that the group of subjects with predominantly linear physique had a significantly higher mean stress cortisol level than the other main group of primarily muscular students, but the latter had a significantly higher mean neuroticism score on the personality test.

Subsequently, another study was carried out in similar circumstances on a further group of students in which a wider range of physiological variables was investigated, and details of this will be reported separately (Bridges, Jones, and Leak, to be published). In order specifically to investigate further the relationship of plasma cortisol levels to personality and physique, these particular aspects have been studied on the combined results of the students in both experiments.

\section{METHOD}

The first experiment included 32 male students taking the second M.B. anatomy viva voce examination. In the second experiment another $\mathbf{4 8}$ students were investigated at the same examination one year later. Thus, the results of 80 male subjects, all of whom were aged about 20 years, are considered here.

In all cases blood was collected $\mathbf{3 0} \mathrm{min}$ after the commencement of the examination, as the peak plasma cortisol response was expected to occur at this time. Some months later the students attended for measurement of physique, completion of the personality inventories, and collection of a sample of blood for control estimations of plasma cortisol under resting conditions. For this purpose situations of excitement and exercise were avoided in the preceding period and some 30 to 60 min were spent resting while completing the psychological test questionnaire before blood was collected. All blood samples were heparinized, then centrifuged immediately after collection, and the plasma was stored at $-20^{\circ} \mathrm{C}$ until assayed. Cortisol was measured by a modification of the spectrofluorimetric method of Zenker and Bernstein (1958). 
The method of phenotyping has been described by Parnell (1958), personality was measured by the Eysenck Personality Inventory, Scale A (E.P.I.) (Eysenck and Eysenck, 1964), which consists of two scores giving results in the dimensions of emotional stability or neuroticism ( $\mathrm{N}$ score) and of extraversion ( $\mathrm{E}$ score).

\section{RESULTS}

The mean results are given in Table $I$. The mean control plasma cortisol level was found to be $19.4 \pm 4.7 \mu \mathrm{g} / 100 \mathrm{ml}$., while the mean stress level was $33.7 \pm 10.2 \mu \mathrm{g}$. These values compare with a normal mean of $14 \mu \mathrm{g} / 100 \mathrm{ml}$., with a range up to about $26 \mu \mathrm{g}$ (Bliss, Sandberg, Nelson, and Eik-Nes, 1953; Mattingly, 1962). The mean resting level was rather high but is within the normal range, the highest control result was $27 \mu \mathrm{g}$ and such increased values might be accounted for by anticipatory anxiety in some subjects, especially related to venepuncture. Not only is the mean stress level raised considerably, but also the variance is increased, which indicates a wide range of responsiveness among the subjects despite the similarity of the stressful situation. The highest value found after stress was $56.6 \mu \mathrm{g}$, and there were six subjects with levels over $50 \mu \mathrm{g}$. It might be expected that the examination would be especially stressful if the student found it difficult, but this was not confirmed, as the mean stress cortisol level for those who failed the examination was $35.2 \mu \mathrm{g}$, which is similar to the mean for all subjects.

The time of collection of all blood samples was noted in order to assess any effect resulting from the diurnal variation of plasma cortisol concentration (Migeon, Tyler, Mahoney, Florentin, Castle, Bliss, and Samuels, 1956). But no pair of samples were taken more than $4 \mathrm{hr}$ apart and most of the differences far exceed any effect of the diurnal rhythm, many being in a reverse direction to the rhythm in any case.

The mean scores on the personality test were $11.9 \pm 4.1$ for extraversion and $9.4 \pm 4.5$ for neuroticism, which compares with the following mean values found for a group of university students: $\mathrm{E}=11.095 \pm 4.5$ and $\mathrm{N}=10.006 \pm 5.0$ 을 (Eysenck and Eysenck, 1964).

The physiques of the students have been grouped $\stackrel{\mathbb{D}}{=}$ according to the primary components. For example, the linear group consists of subjects with either secondary fatness (Lf), secondary muscularity $(\mathrm{Lm})$, or both these secondary components equal (L) Similarly, there is a muscular group and a smallo group with primary fatness. There then remain $14 \stackrel{\mathrm{0}}{7}$ subjects not included, most of whom possess two equal primary components $(\mathrm{ML}=6, \mathrm{FM}=4, \overrightarrow{\mathrm{F}}$ $\mathrm{LF}=3$, Central $(444)=1)$. The mean results for the three main groups into which the subjects are? arranged are given in Table I. The only statistically $\frac{\overline{\bar{\sigma}}}{\mathrm{s}}$ significant difference between the groups is the $\frac{\text { क }}{\widetilde{\sigma}}$

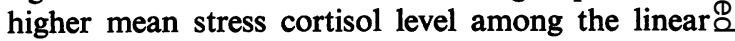
subjects compared with the muscular group.

Table II gives the correlation coefficients between $\rightarrow$ the various parameters. Significant negative correl- ations were found, as expected, between the three $\vec{\omega}$ anthropometric measures and it is of interest that these coefficients are similar to the comparable ones $\overline{3}$ reported by Sheldon (1942) for the somatotypes of 200 subjects, which were as follows: $F$ v. $M=0 \cdot 29,$. $F$ v. $L=0.41$, and $M$ v. $L=0.63$.

Whereas in our previous study no other variabre was found to correlate with the stress cortisol leve in the present larger group there is a significa角 negative correlation with the degree of muscularity. Also, a significant positive correlation was foundo between the control cortisol levels and the neuroficism scores. In the previous study we found that the linear group had a significantly lower meallo neuroticism score than the muscular group and that the linear component was significantly negatively correlated with the $\mathbf{N}$ score. In the present largero group the trends are similar but are no longer statistically significant, so that this rather anomalouso finding has not been confirmed.

\section{DISCUSSION}

There have been previous studies attempting to relate corticosteroids and anthropomorphology

TABLE I

MEAN RESULTS

\begin{tabular}{|c|c|c|c|c|c|c|c|c|}
\hline \multirow[t]{2}{*}{ Phenotype group } & \multirow[t]{2}{*}{ No. } & \multicolumn{2}{|l|}{ E.P.I. } & \multicolumn{3}{|c|}{ Phenotype } & \multicolumn{2}{|c|}{$\begin{array}{l}\text { Plasma cortisol } \\
\text { (ug/100 ml.) }\end{array}$} \\
\hline & & E Score & N Score & $\boldsymbol{F}$ & $M$ & $L$ & Control & Stress \\
\hline $\begin{array}{l}\mathbf{L}, \mathbf{L m}, \mathbf{L f} \\
\mathbf{M}, \mathbf{M l}, \mathbf{M f} \\
\text { F, Fl, Fm }\end{array}$ & $\begin{array}{r}21 \\
37 \\
8\end{array}$ & $\begin{array}{l}11.6 \pm 4.6 \\
11.9 \pm 3.7 \\
13.0 \pm 4.2\end{array}$ & $\begin{array}{r}8.1 \pm 3.8 \\
10.1 \pm 4.5 \\
11.5 \pm 3.6\end{array}$ & $\begin{array}{l}2 \cdot 6 \\
3 \cdot 1 \\
5 \cdot 3\end{array}$ & $\begin{array}{l}3 \cdot 4 \\
5 \cdot 1 \\
3 \cdot 1\end{array}$ & $\begin{array}{l}5 \cdot 0 \\
2 \cdot 9 \\
2 \cdot 5\end{array}$ & $\begin{array}{l}17.6 \pm 4.8 \\
20.0 \pm 4.3 \\
17.6 \pm 5.9\end{array}$ & $\begin{array}{l}37.7 \pm 12.5^{*} \\
31.0 \pm 9.4^{*} \\
33.0 \pm 9.8\end{array}$ \\
\hline $\begin{array}{l}\text { All subjects } \\
* P<0.05\end{array}$ & 80 & $11.9 \pm 4.1$ & $9 \cdot 4 \pm 4 \cdot 5$ & $3 \cdot 2$ & $4 \cdot 2$ & 3.6 & $19 \cdot 4 \pm 4 \cdot 7$ & $33.7 \pm 10.2$ \\
\hline
\end{tabular}


TABLE II

CORRELATION COEFFICIENTS

$\begin{array}{llllll}1 & 2 & 3 & 4 & 5 & 6\end{array}$

1. Control cortisol

2. Stress cortisol

3. E score

4. $N$ score

5. Fat

6. Muscle

7. Linearity

8. Height

9. Weight

0.067
0.158
$0.219^{*}$
-0.009
0.121
-0.169
-0.168
-0.048
$+P<0.001$
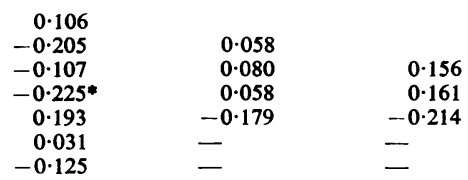

$-0.269 t$
$-0.438 t$
-

$-0.500 \ddagger$

$* P<0.05$

For example, Tanner, Healy, Whitehouse, and Edgson (1959) employed various anthropometric measures which were related to the 24-hr excretion of 17-ketosteroids and 17-ketogenic steroids in young men. The excretion of 17-ketosteroids was significantly related to body weight and muscularity, while that of 17-ketogenic steroids was correlated with weight and height. Similar investigations were carried out by De Moor, Steeno, Hendrikx, and Ostyn (1964) who studied corticosteroid excretion in men and women, making comparisons with 29 discrete physical measurements. These reports, unlike the present investigation, have not been concerned with stress responsiveness. In the present group of subjects neither the control plasma cortisol levels nor those after stress were significantly related to overall measures of body size such as height and weight.

It can be seen that there are a number of methodological problems in these studies which make comparison difficult. Certainly plasma steroid levels give a more reliable estimate of adrenocortical activity than the urinary excretion of steroid metabolites, but only at a moment of time, while urinary estimations give a measure over longer periods. In addition, 24-hr levels may present a total picture of resting activity in which casual stresses are rendered less important. Some anthropometric measures offer more meaningful relationships in this context than others, and it might be expected that the least value derives from specific physical measurements. The problem of reliable anthropometric quantification has not yet been satisfactorily solved, and phenotyping, although probably giving a satisfactory composite estimate, is a relatively crude measure of complex physical characteristics. In studying a group of medical students definite selection factors must operate in relation to both personality and physique, and each show relative homogeneity within the present group. But with these limitations, the findings confirm some previous reports and have interesting implications.

Firstly, a positive correlation has been found between the control plasma cortisol levels and the neuroticism score of the E.P.I. It is likely that these control levels were influenced by mild anticipatory anxiety in some subjects and that they were not basal values. Perhaps for this reason there is no correlation with height or weight as previous work has suggested. It would appear that in this experimental situation those subjects with a greater tendency to emotional instability, shown by their higher $\mathrm{N}$ scores, tend to have related raised cortisol levels and therefore seem to be experiencing more anxiety. But this tendency to emotional instability is only relative within this normal group as no abnormally high scores were recorded among the subjects.

Secondly, the plasma cortisol levels after the stress of the examination were found to have a negative correlation with muscularity, so that the more muscular students presumably experienced less anxiety. As muscularity and linearity are negatively correlated the group of primarily linear students appear to have felt more anxiety and therefore had higher cortisol levels than the muscular group. In this relationship the muscle component appears to be more fundamental than linearity.

However, the primarily fat group of students also showed a lower mean stress cortisol level similar to that of the muscular group, although their mean muscular component was similar to that of the linear group. It is therefore possible that higher degrees of fatnessare also associated with lower anxiety responses to stress, but no reliable conclusions are possible because of the small number of subjects in this group. This low incidence of fatness among the students confirms a previous observation (Parnell, 1953) that undergraduates tend to have low fat components and medical students in particular have high muscularity ratings with low fatness.

A tendency to experience greater anxiety under stress may well be related to a predisposition to psychiatric illness, some forms of which are known to be associated with certain types of body build. The present findings confirm previous reports by Parnell (1957) who compared the physiques of a 
group of healthy students with another group who had been advised to have psychiatric treatment, and found the latter contained six times as many subjects with a primarily linear physique (Lf), while those with primary muscularity (Mf) were five times more common among the healthy subjects. Parnell (1958, p. 75$)$ has also reported that the highest incidence of psychiatric illness in young men occurs among those with very low muscular components, and that anxiety states seem to be rare in patients whose fat or muscular components are high and rated 5 or more (Parnell, 1958, p. 90).

Although the neuroticism scores correlate positively with the control cortisol levels, there is a negative and insignificant relationship with the stress cortisol levels. An explanation of this finding might be that the degree of neuroticism relates to psychological sensitivity to stress, and is therefore of importance in the circumstances of the minor stress of the control observations when only those with relatively higher neuroticism scores felt anxious. At the examination, when very high psychological stress prevailed, sensitivity of perception of the stress was unimportant in relation to some intrinsic anxiety responsiveness to it, shown by associated increased adrenocortical activity, which proved to be more closely related to a low degree of body muscularity.

The sensitivity of plasma cortisol concentration as a measure of anxiety is not known in detail and it is possible that the high levels found do not necessarily accurately reflect the degree of anxiety experienced but merely indicate the physiological sensitivity of adrenocortical responsiveness in the individual subject, which might be expected to have physical associations with body build. It is also possible that in conditions of stress muscle volume has some effect on the level of circulating cortisol. Clarification of these points will require further investigation, which is being carried out.

\section{SUMMARY}

The plasma cortisol levels of 80 medical students were measured after the stress of viva voce examinations, as an indication of the anxiety they experienced. In addition, control cortisol levels were measured during resting conditions on another occasion. The mean control level was found to be $19.4 \pm 4.7 \mu \mathrm{g} / 100 \mathrm{ml}$. and the mean stress value was $33 \cdot 7 \pm 10 \cdot 2 \mu \mathrm{g}$.

The cortisol results were related to measures of physique and of personality in order to investigate factors which might be associated with the degree of anxiety experienced, which appeared to vary widely.
The control cortisol levels were significantly pos $z$ itively correlated with the neuroticism scores of the Eysenck Personality Inventory, and the stress cortiso $\bar{b}$ levels were significantly negatively correlated with the degree of muscularity assessed by phenotyping? Possible explanations of these relationships are given? and the results tend to confirm some previous studies relating body build with psychiatric illness. It is suggested that there is an intrinsic sensitivity in anxiety response to psychological stress that has an important association with physique.

We are grateful to the Dean of St. Thomas's Hospita Medical School, Mr. R. W. Nevin, and to Professo $\overline{\bar{n}}$ D. Davies for their kind cooperation and permission tob carry out the study. We thank Dr. A. Elithorn, of the Royal Free Hospital, for facilities made available in his department, and also the medical students who soreadily volunteered to take part in the investigation. We are indebted to Mrs. D. Pateman and Mr. J. Bermudez for technical assistance and to Miss G. Rattey fop secretarial help. P. K. Bridges was supported by a grant from the Royal Free Hospital Endowment Fund an M. T. Jones by a grant from the Medical Researctio Council.

\section{REFERENCES}

Bliss, E. L., Sandberg, A. A., Nelson, D. H., and Eik-Nes, K. (1 The normal levels of 17-hydroxycorticosteroids in the ipheral blood of man. J. clin. Invest., 32, 818-823.

Bridges, P. K., and Jones, M. T. (1967). Personality, physique andhhe adrenocortical response to a psychological stress. Brif Psychiat., 113, 601-605.

Eysenck, H. J., and Eysenck, S. B. G. (1964). Manual of the EyserckPersonality Inventory. University of London Press, Londom

Kretschmer, E. (1936). Physique and Character, 2nd ed., Kegan Făfọ London.

Mattingly, D. (1962). A simple fluorimetric method for the estimation of free 11-hydroxycorticoids in human plasma. J. clin. Path? 15, 374-379.

De Moor, P., Steeno, O., Hendrikx, A., and Ostyn, M. $(1964)$ Anthropomorphology and corticosteroid excretion in normat young adult males and females. Acta clin. belg., 19, 334-338.

Migeon, C. J., Tyler, F. H., Mahoney, J. P., Florentin, A. A., Castle H., Bliss, E. L., and Samuels, L. T. (1956). The diurnal variation of plasma levels and urinary excretion of 17-hydroxycort $\bar{B}$ costeroids in normal subjects, night workers and bling subjects. J. clin. Endocr., 16, 622-633. Parnell, R. W. (1953). Physique and choice of faculty. Brit. med. J.,
472-475.

(1957). Physique and mental breakdown in young adults. Brit. med. J., 1, 1485-1490.

- (1958). Behaviour and Physique. Arnold, London.

Rees, L. (1960). Constitutional factors and abnormal behaviour. If Handbook of Abnormal Psychology, edited by H. J. Eysencl Pitman Medical Publishers, London.

Sheldon, W. H. (1940). The Varieties of Human Physique. Harper? New York.

(1942). The Varieties of Temperament. Harper, New York.

Tanner, J. M., Healy, M. J., Whitehouse, R. H., and Edgson, A. G (1959). The relation of body build to the excretion of 1 t ketosteroids and 17-ketogenic steroids in healthy young mens J. Endocr., 19, 87-101.

Zenker, N., and Bernstein, D. E. (1958). The estimation of smati. amounts of corticosterone in rat plasma. J. biol. Chem., 23N 695-701. 